\title{
FIELD INVESTIGATION IN THE DETONATION BEHAVIOR OF EMULSION EXPLOSIVE COLUMN INDUCED WITH AIR GAPS
}

\author{
Vineeth BALAKRISHNAN*, Manoj PRADHAN, \\ P.Y. DHEKNE \\ Department of Mining Engineering, National Institute of Technology, Raipur 492010, India
}

\begin{abstract}
In blasting of soft to medium hard rock, the problem of high density resulting in excessive utilization of emulsion explosive is well known. The authors have conducted some experimental blasts to delve into the detonation behavior of conventional blasting and various other explosive consumption reduction techniques which induce air gaps using plastic tubes, plastic bottles or plastic balls in the explosive column. Resistance wire technique is used for gauging in-hole continuous velocity of detonation. The VOD varies from $5321.6 \mathrm{~m} / \mathrm{s}$ to $4544.2 \mathrm{~m} / \mathrm{s}$ and from $5123.4 \mathrm{~m} / \mathrm{s}$ to $4274.2 \mathrm{~m} / \mathrm{s}$ in conventional site mixed emulsion column and distributed spherical air gap column respectively. The detonation behavior is stable and similar in both these cases. While using plastic bottles or plastic tubes as air gaps, the VOD is fluctuating from $4636.3 \mathrm{~m} / \mathrm{s}$ to $3268.4 \mathrm{~m} / \mathrm{s}$ and from $4935.9 \mathrm{~m} / \mathrm{s}$ to $3362.8 \mathrm{~m} / \mathrm{s}$ respectively with a collapse of about $12 \%$ from the average VOD of conventional SME column. The VOD falls abruptly when the detonation wave encounters large air gaps but it is successfully travelling through the air gaps making the detonation behavior more capricious.
\end{abstract}

Keywords: velocity of detonation (VOD), site mixed emulsion (SME), distributed spherical air gap (DAG) blasting

\section{INTRODUCTION}

The VOD is a speed at which the detonation wave travels through a column of explosive (Bhandari 1997). The VOD of an explosive not only controls the rate of release of explo-

Corresponding authors: Discovervineeth@gmail.com

doi: $10.37190 / \mathrm{msc} 192605$ 
sive energy but also influences the energy partitioning with respect to shock and heave energy (Berta, 1990). VOD is an important indicator of the performance of an explosive. It is influenced by many factors such as explosive confinement, formulation, sensitizing agents, density, diameter of borehole, primer type and size, sleep time in borehole, dynamic desensitizing effects, blast environment, drop impact in borehole, temperature, borehole loading technique, blast design, length of explosive column, storage, transportation, mixing in bulk loading system, manufacturing etc. (Chiappetta, 1988). Other significant contribution in this field includes the researches of Cooper (1996), Cunningham (2006), Mesec et al. (2015), Xu et L. (2016), Zang (2016), Oluwoye et al. (2017), Zhu et al. (2017), Strizhak et al. (2017), Qiujie et al. (2017), Wang et al. (2018), etc.

The VOD in confined condition is much higher than the VOD determined in unconfined space. VOD increases with increase in confinement to a critical value beyond which confinement has no appreciable effect on VOD (Clark 1971). Shen Ying et al. concluded that the maximum VOD of emulsion explosive in confined space is higher than that in unconfined space (see Xuguang 1994).

Explosive formulations include the ingredients that are used for its manufacturing, their quality and proportion. Clark found that the detonation velocity is maximum with a fuel oil content slightly less than oxygen balance (Clark 1971). The studies conducted by Cudzilo et al. (2002) showed that partial substitution of ammonium nitrate with nickel nitrate $(\mathrm{AN}-\mathrm{NiN}) /$ calcium nitrate $(\mathrm{AN}-\mathrm{CaN}) /$ sodium nitrate $(\mathrm{AN}-\mathrm{NaN})$ in emulsion matrix caused a substantial decrease in the VOD. Xuguang (1994) reported that the VOD of emulsion explosive decreased with increasing aluminum content.

Emulsion explosives uses gas bubbles for sensitization. Xuguang (1994) reported that perlite sensitized emulsion have lower VOD than glass microballoons (GMB) sensitized emulsion explosive. Hattori et al. reported that the VOD of emulsion explosive increases as the size of GMB is decreasing for all the values of density (Hattori et al. 1982).

The charge density is another important factor that has a strong influence on the VOD. Lee et al. (1989) found that the VOD of GMB sensitized emulsion increased with an increase in the initial density up to a maximum value, then rapidly decreases and fails. The failure diameter also increased with increase in density.

The charge diameter also influences the VOD of commercial explosives. Oucheterlony et al. (1997) reported that the VOD of commercial explosive increases with increase in charge diameter.

The type and size of the primer also have a strong influence on the VOD of the explosives. The explosive initiated with a primer of low detonation pressure, detonates with low VOD. The diameter of the primer must be more than the critical diameter of the column charge; otherwise explosive in the column charge detonates with lower VOD (Konya, Walter 1990). Gilitner (2003) showed that as the mass of the booster is increased, the VOD also increases. Further, the VOD became more stable with increase in booster size.

The sleep time of explosive also affects its VOD. The sleep time is the time period between the charging of the blast hole and firing of the explosive. Nabiullah et al. 
(2005a) reported that emulsion explosive having matrix viscosity $40000-45000 \mathrm{cP}$ fails to detonate after a sleep time of 18 days whereas emulsion explosive having viscosity 75000-80000 cP detonated even after a sleep time of 24 days. Pradhan (2010) reported 10\% drop in VOD of bulk emulsion both in laboratory and field environment for a sleep time of 15 days.

Blast design parameters like burden and spacing of second and subsequent rows may cause dynamic desensitization effect, if not properly designed. Sumiya et al. (2002) found that the VOD of pre-compressed emulsion explosive is low as compared to that of the un-compressed explosives. A pre-compressed emulsion explosive is under any static or dynamic pressure inside the borehole before initiation whereas an uncompressed explosive is not under any such pressure. Shulin (1993) found that emulsion explosive tolerates a pressure of up to $17 \mathrm{MPa}$ before it is dead pressed.

Water based explosives like slurry and emulsion have excellent water resistance properties. However, they may get diluted, desensitized or float up on the water column in watery holes (Ray 1991). Nabiullah et al. (2005b) reported a fall of about 6 to $10 \%$ in VOD under shallow water conditions. Nabiullah et al. (2005a) investigated the effect of $\mathrm{pH}$ of water and reported that the VOD of straight explosives fell with acidity of water. The study reported similar fall in VOD for doped explosive also, which is a blend of emulsion explosive and ammonium nitrate. Many other researchers have been conducted to identify the factors effecting VOD (Gong et al. 2017; Mishra at al. 2018; Kabwe, Chanda 2018, Mertuszka et al. 2018), etc.

The bulk emulsion explosives are dominating the market of explosives. The only demerit of emulsion explosive is its high density. Because of high density, when emulsion explosives are used in soft to medium hard and easy-to-blast rocks, more explosive is utilized. Identifying the problems, many researchers have developed techniques to decrease the explosive consumption. The air decking technique is one such popular technique of explosive consumption reduction (Melnikov, Marchenko 1971; Melnikov et al. 1976; 1979; Marchenko 1982). In this technique air decks are introduced using wooden or plastic spacers with diameter equivalent to the borehole diameter, resulting in a complete non explosive zone inside the charge column. This technique is generally not preferred in holes of 9-10 $\mathrm{m}$ depth as it is a time consuming process, which requires more physical labor. It also requires initiations at two different points.

In India some methods such as use of plastic tubes (Kim et al. 2005) and use of discarded plastic bottles (Pradhan, Pradhan 2013; Pradhan et al. 2015) for inducing air gaps in the explosive column are attempted for reducing explosive consumption. Though these techniques have shown some encouraging results they suffer from some drawbacks due to improper distribution of the voids in the explosive column. The detonation behavior due to such air gaps in the explosive column is also not investigated. Using these techniques, it is also difficult to engineer a process of modifying the loading density of explosive in the site according to the geological requirement of the mine. The continuous availability of bottles is a major challenge for the mine as 
there are no collections centers available in India. The bottles are collected from various dirty and unhygienic surroundings which make the process aesthetically more difficult to perform. The mechanization of these techniques is difficult resulting in generation of possible bottle neck in otherwise swift blasting process.

To address these problems the authors have conceptualized an innovative technique called distributed spherical air gap (DAG) blasting which is in its developing phase. This technique is thought to provide distributed and uniform air gaps. It is therefore necessary to investigate the detonation behavior of this technique. In this paper the detonation behavior of DAG blasting is studied and a comparative evaluation of this novel technique is also presented for detonation behavior of the explosive column resulted due to conventional site mixed emulsion (SME) technique, plastic tube technique and plastic bottle technique.

\section{MATERIALS AND METHODS}

The field study is performed in Century Cement Limestone mine at Baikunth in Raipur district of Chhattisgarh state in India. The conventional drilling and blasting technique is used for rock breakage.

The usual practice of the mine is to charge the holes with SME. 17 milliseconds hole-to-hole delay, 42 milliseconds row-to-row delay, and 250 milliseconds down-thehole delay are used in all the blasts. The hole diameter, average hole depth, average spacing and average burden are $0.115 \mathrm{~m}, 9.0-9.5 \mathrm{~m}, 5.0 \mathrm{~m}$ and $4.0 \mathrm{~m}$, respectively. Three cartridge boosters are used in each column. Each of the cartridge boosters has a weight of $0.50 \mathrm{~kg}$, density of $1250 \mathrm{~kg} / \mathrm{m}^{3}$ and rated VOD of $4800 \mathrm{~m} / \mathrm{s}$. The shock tube system is used for initiation. For the purpose of this research, except in case of conventional SME column about $20 \%$ explosive by volume is replaced by nonexplosive materials in every other trial blast.

The explosive used by the mine is used in this research which is a double salt emulsion. The oxidizer blend (OB) comprised of aqueous solution of $73.0 \%$ of ammonium nitrate, $3.0 \%$ of sodium nitrate, $0.1 \%$ thio-urea and $17.7 \%$ water. The fuel blend (FB) comprises of $2.0 \%$ light diesel oil, $2.9 \%$ furnace oil and $1.3 \%$ of sorbitol mono oleate. The physical properties of emulsion matrix used in the study are presented in Table 1 . Aqueous sodium nitrate solution ( $10 \%$ by weight) with formaldehyde solution ( $7 \%$ by weight) is used as gassing agent. The amount of gassing agent used is about $1 \%$ of the weight of emulsion matrix. For all trial blasts initial matrix temperatures are between $333.15-338.15 \mathrm{~K}$. The initial matrix density is about $1300 \mathrm{~kg} / \mathrm{m}^{3}$ whereas the final density is about $1150 \pm 50 \mathrm{~kg} / \mathrm{m}^{3}$. The unconfined VOD of the explosive is $4000 \pm 500 \mathrm{~m} / \mathrm{s}$.

Rock confined VOD (in-hole) is measured using HandiTrap-II VOD recorder of MREL Special Explosive Products Limited, Canada. The HandiTrap-II is a portable, 
single channel, and high resolution explosives continuous VOD recorder. It uses continuous resistance wire technique for monitoring VOD. A probe-cable of known linear resistance is placed axially in the explosive column. As the detonation front of the explosive consumes the probe-cable, the resistance of the circuit will decrease in proportion to the reduction in length of the probe-cable. The HandiTrap-II records the resulting decrease in voltage across the probe-cable versus time. For measuring the inhole VOD, the probe-cable, $30 \mathrm{~m}$ long and shorted out at one end is used. The short circuit end of the cable is attached to the primer and lowered into the hole. About $6 \mathrm{~m}$ length of the cable is in explosive column. The hole is then charged with explosive. The blast hole is later stemmed as per usual procedure. For connecting the Handitrap-II with probe cable, connections are made shielding to shielding and conductor to conductor. The HandiTrap-II is later placed in a protective shelter near the blast area. Figure 1 shows the snapshot of VOD measurement using Handitrap-II. For the purpose of this research in-hole continuous VOD is measured for complete SME column, SME column induced with hollow plastic tubes, SME column induced with hollow plastic bottles and DAG column.

Table 1. Physical properties of emulsion matrix used in the study

\begin{tabular}{|l|c|}
\hline \multicolumn{1}{|c|}{ Properties of Emulsion Matrix } & Observations \\
\hline Colour & Blackish \\
\hline Appearance & Greasy \\
\hline Initial matrix density & $1390 \mathrm{~kg} / \mathrm{m}^{3}$ \\
\hline Initial matrix temperature & $348.15 \mathrm{~K}$ \\
\hline Viscosity & $10400 \mathrm{cP}$ \\
\hline $\mathrm{pH}$ & $2.5-3.0$ \\
\hline Fudge point & $313.15-318.15 \mathrm{~K}$ \\
\hline
\end{tabular}
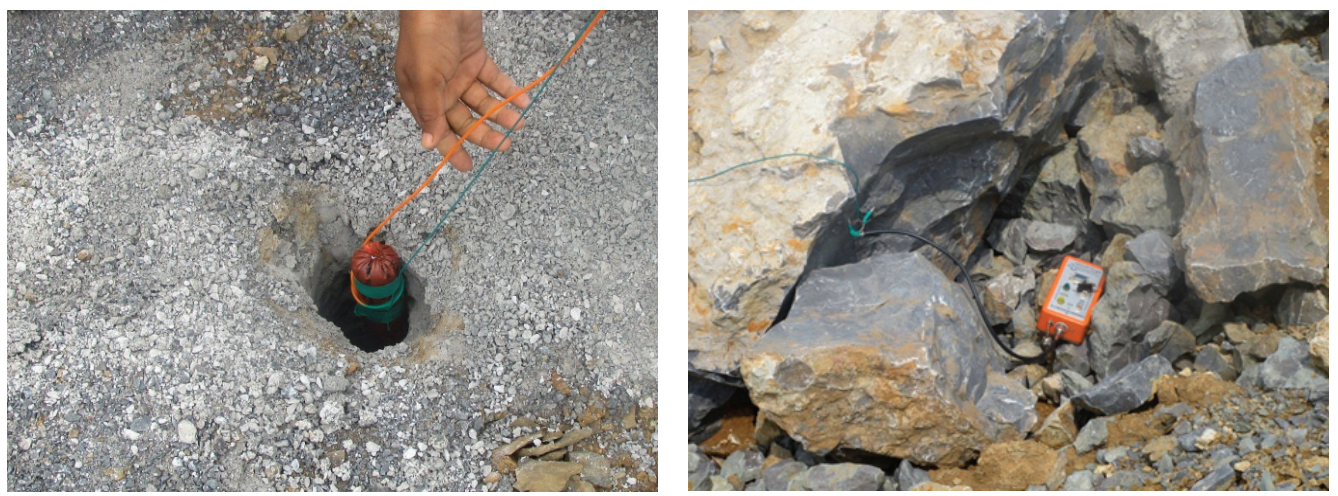

Fig. 1. Snapshot of VOD measurement using Handitrap-II 


\section{EXPERIMENTATION}

\subsection{CONVENTIONAL BLASTING}

The conventional blasting technique is charging of blast hole with explosive to a certain height. The rest of the bore hole is stemmed using drill cuttings. Figure $2 \mathrm{a}$ presents the vertical section of the blast hole charged with SME. Figure $2 \mathrm{~b}$ presents the snapshot of charging process. The analysis of continuous VOD curve at every $0.5 \mathrm{~m}$ interval from the bottom of explosive column for the complete SME column is presented in Fig. 3. The average in-hole VOD for the entire SME column is around $4777 \mathrm{~m} / \mathrm{s}$.

(a)

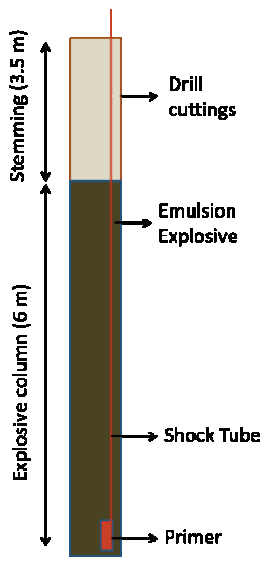

(b)

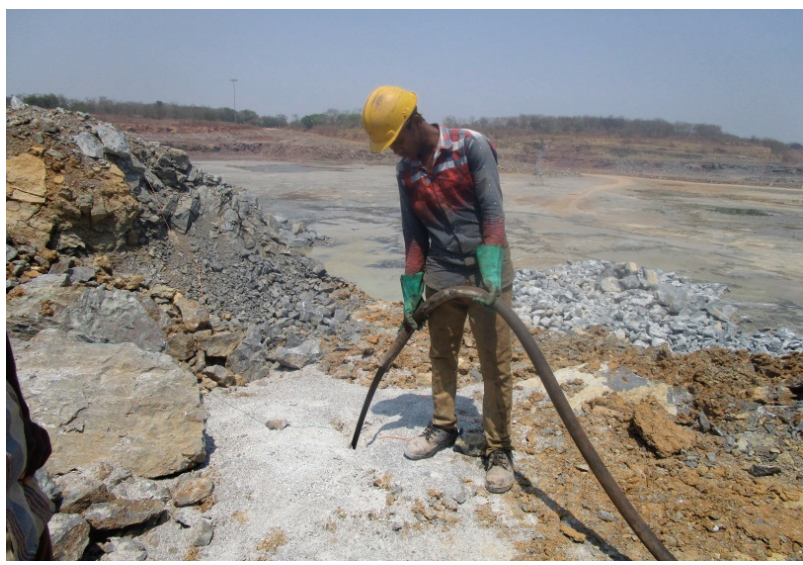

Fig. 2. (a) Vertical section of the blast hole charged with SME, (b) Snapshot of charging process

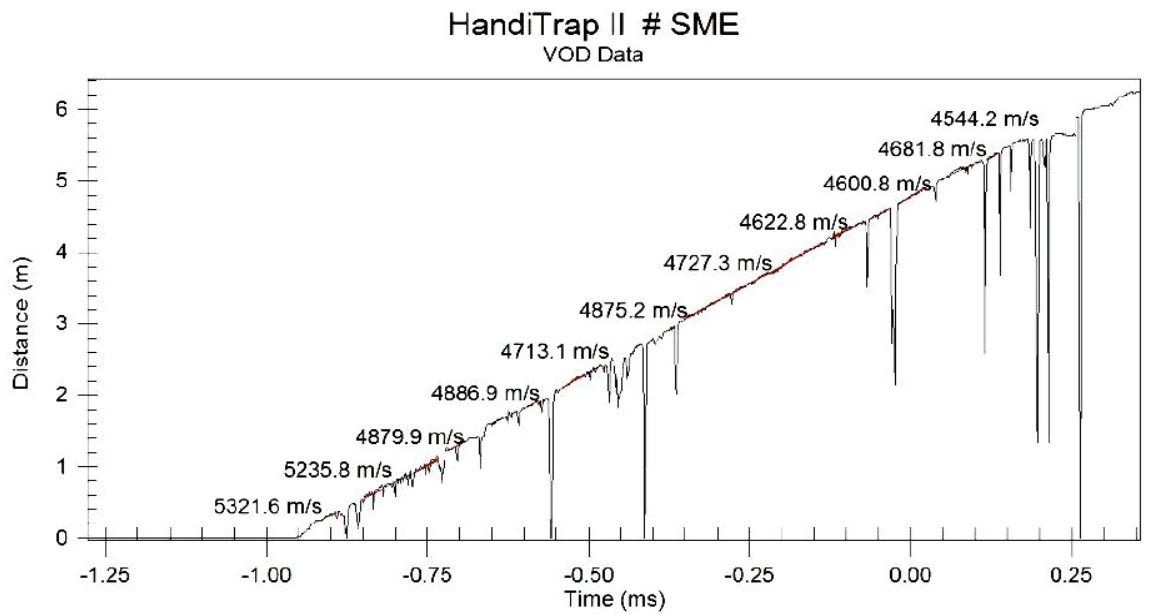

Fig. 3. Analysis of continuous VOD curve for complete SME column 


\subsection{PLASTIC TUBE TECHNIQUE}

In this method, plastic tubes are used to introduce air gaps. Four plastic tubes are inserted manually at fixed time intervals during charging of hole to save about $20 \%$ of explosive by volume. These tubes have $0.083 \mathrm{~m}$ diameter, $0.50 \mathrm{~m}$ length and $0.018 \mathrm{~kg}$ weight. Figure $4 \mathrm{a}$ shows the vertical section of the blast hole induced with the plastic tubes in between the SME column. Figure 4b) shows the snapshot of plastic tubes used in this experiment. The average in-hole VOD of the SME column when induced with plastic tubes is around $4244 \mathrm{~m} / \mathrm{s}$. The analysis of the continuous VOD curve at every $0.5 \mathrm{~m}$ interval from the bottom of explosive column for SME column induced with plastic tubes is presented in Fig. 5.

(a)

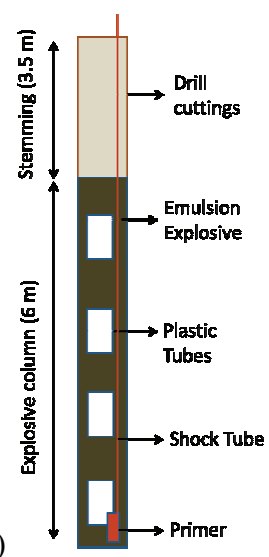

(b)

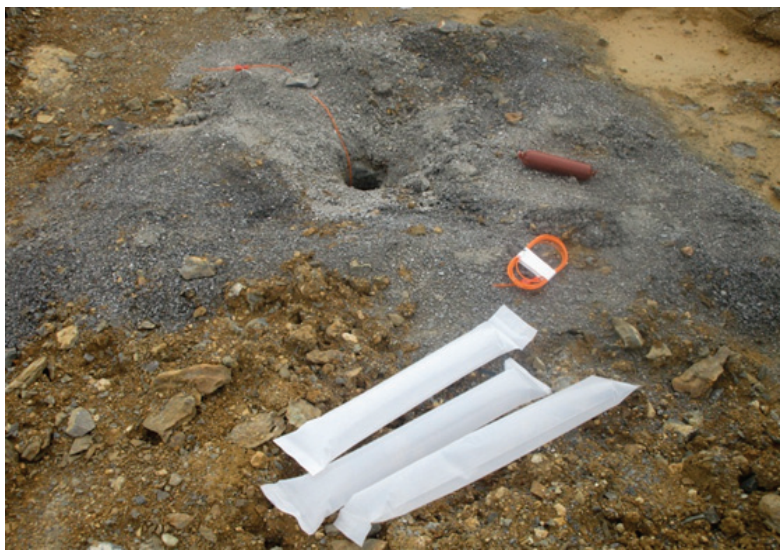

Fig. 4. (a) Vertical section of the blast hole induced with plastic tubes in SME column, (b) Snapshot of the plastic tubes used in the experiment

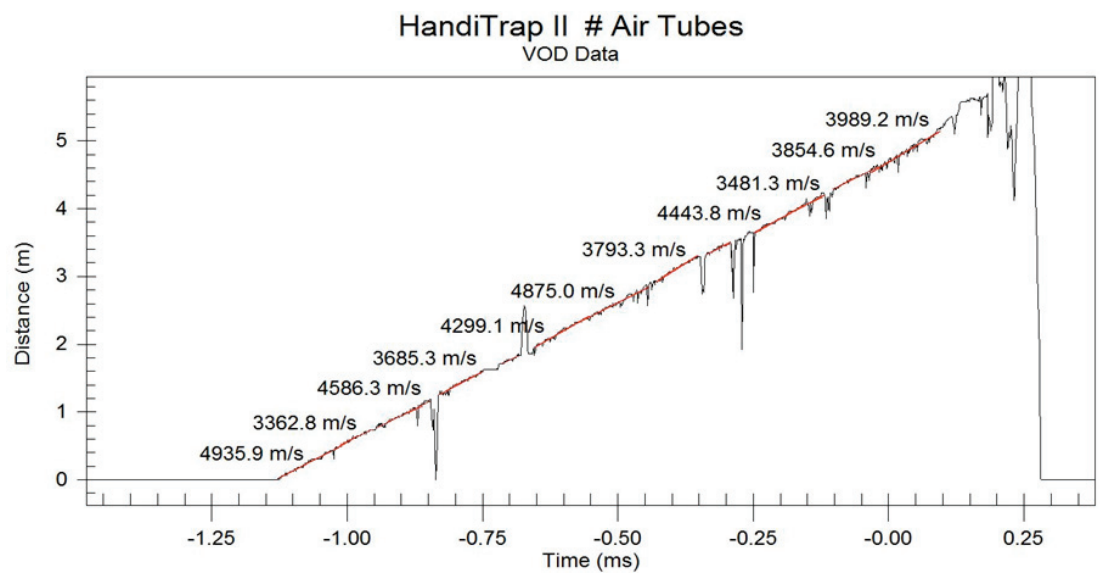

Fig. 5. Analysis of continuous VOD curve for SME column induced with plastic tubes 


\subsection{PLASTIC BOTTLES TECHNIQUE}

In this method, empty plastic bottles are used to induce air gaps in the SME column. The maximum diameter and length of the bottle are about $0.076 \mathrm{~m}$ and $0.270 \mathrm{~m}$, respectively. The mass of each bottle is around $0.021 \mathrm{~kg}$. Fifteen bottles are inserted manually at fixed time intervals during charging of hole to save about $20 \%$ explosive by volume. Figure 6a shows the vertical section of the blast hole induced with plastic bottles in between the SME column. Figure $6 \mathrm{~b}$ shows the snapshot of bottles used in the experiment. The average in-hole VOD of the SME column induced with bottles is around $4206 \mathrm{~m} / \mathrm{s}$. The analysis of the continuous VOD curve at every $0.5 \mathrm{~m}$ interval from the bottom of explosive column for SME column induced with plastic bottles is presented in Fig. 7.

(a)

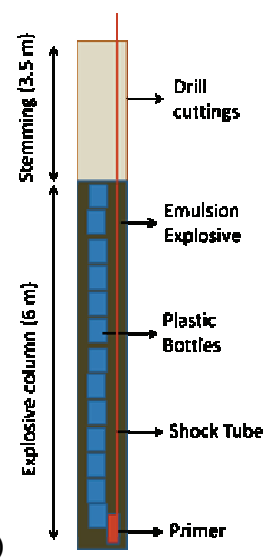

(b)

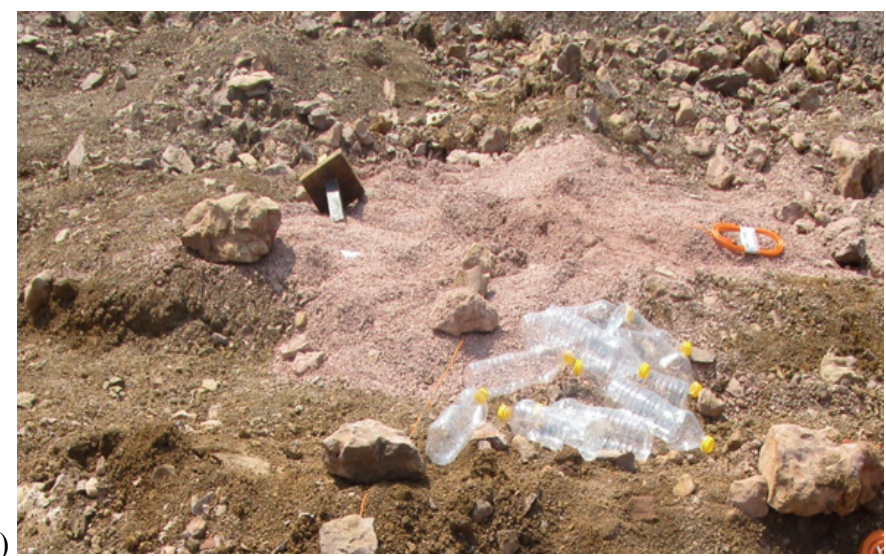

Fig. 6. (a) Vertical section of the blast hole induced with plastic bottles in SME charge column,

(b) Snapshot of the bottles used in the experiment

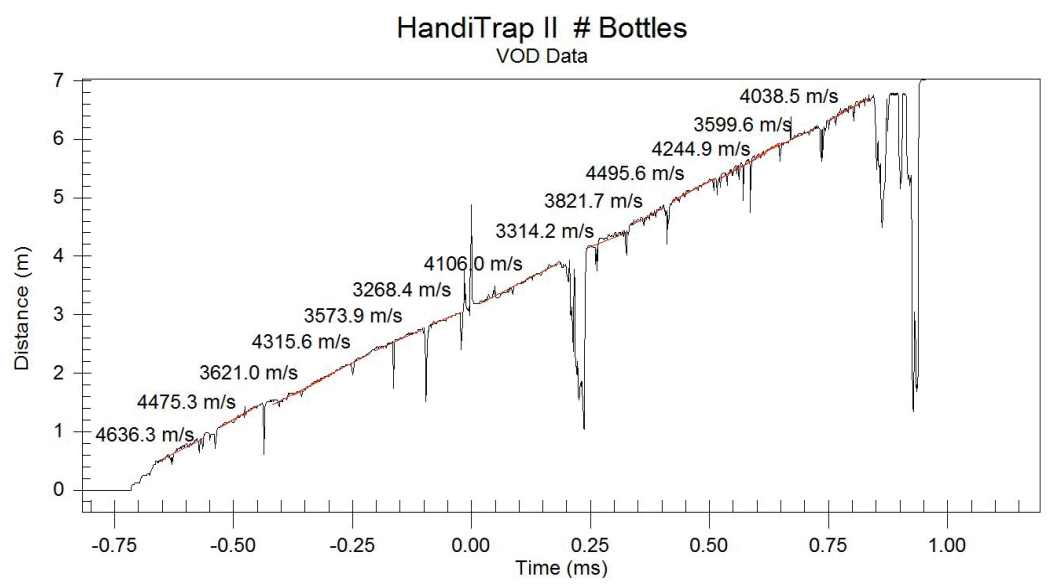

Fig. 7. Analysis of continuous VOD curve for blast hole induced with plastic bottles in the SME column 


\subsection{DISTRIBUTED SPHERICAL AIR GAP BLASTING}

This is an innovative method developed by the authors. It is abbreviated as DAG blasting. In this method hollow balls made from recycled plastic waste are used to induce air gaps in the explosive column. Due to their smaller size, these balls are well distributed throughout the SME column, maintaining the continuity in detonation column. The diameter of ball is about $0.0390 \mathrm{~m}$ with mass of around $0.997 \mathrm{~g}$. In DAG columns, four hundred balls are induced manually at fixed time intervals during charging of hole to save about $20 \%$ explosive. Figure 8 a shows the vertical section of the DAG column. Figure $8 \mathrm{~b}$ shows the snapshot of plastic balls used in in this experiment. The average in-hole VOD of DAG column is around $4641 \mathrm{~m} / \mathrm{s}$. The analysis of the continuous VOD curve at every $0.5 \mathrm{~m}$ interval from the bottom of explosive column for DAG column is presented in Fig. 9.

(a)

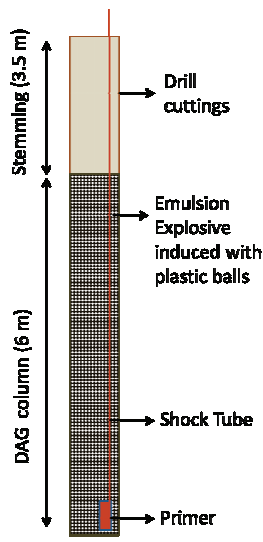

(b)

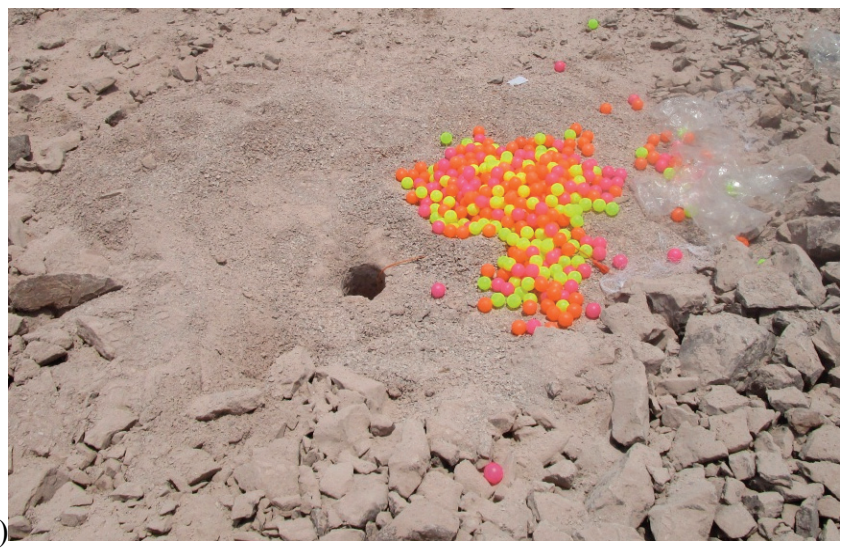

Fig. 8. (a) Vertical section of the DAG column, (b) Snapshot of the plastic balls used in this experiment

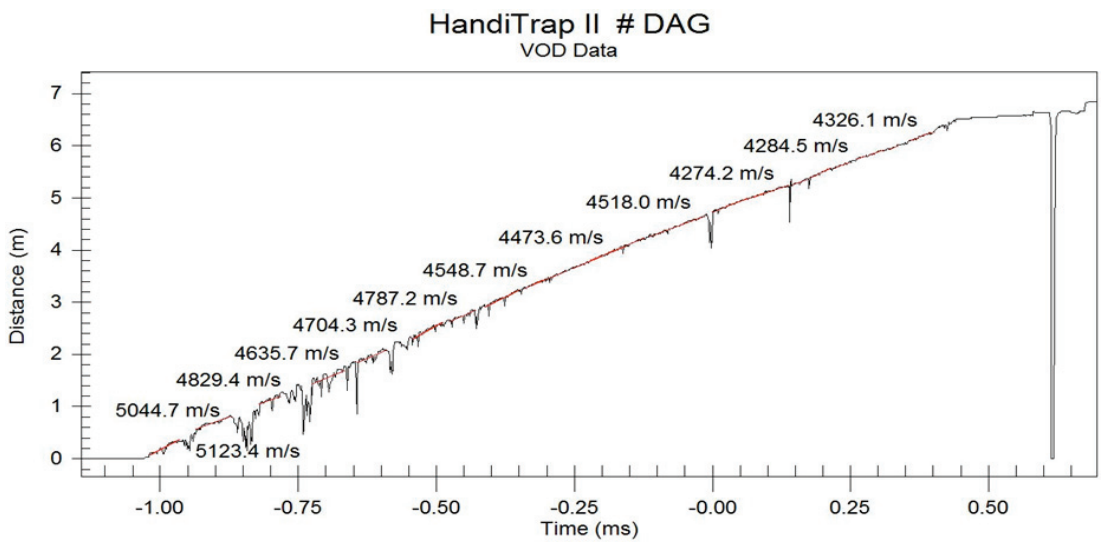

Fig. 9. Analysis of continuous VOD curve for DAG column 


\section{RESULT AND DISCUSSION}

The trial blasts are carried out in similar geo-technical environment by incorporating air gaps either with balls or bottles or tubes. The application of different materials viz. balls, bottles and tubes ensured changes in the size and shape of the air gap. The materials are introduced manually at constant pace during the time of charging of blast holes. The plastic balls are well distributed in the matrix due to their smaller size, whereas the use of plastic bottles and plastic tubes led to large and nearly cylindrical air gaps at their respective locations in the SME column. Table 2 summarizes the VOD measurement for various explosive composition reduction techniques. The in-hole continuous VOD of the SME with different types of air gaps is measured and analysed. The comparative graph is plotted (Fig. 10) to know the average VOD at locations which are at $0.5 \mathrm{~m}$ interval from the bottom of explosive column for various methods.

Table 2. Summary of the VOD measurements for various explosive consumption reduction techniques

\begin{tabular}{|l|c|c|c|c|c|c|c|}
\hline \multicolumn{1}{|c|}{$\begin{array}{c}\text { Method } \\
\text { of charging } \\
\text { the column }\end{array}$} & $\begin{array}{c}\text { No. } \\
\text { of air gaps } \\
\text { used/hole }\end{array}$ & $\begin{array}{c}\text { Explosive } \\
\text { charged/ } \\
\text { hole, kg }\end{array}$ & $\begin{array}{c}\text { Column } \\
\text { charge } \\
\text { length, } \mathrm{m}\end{array}$ & $\begin{array}{c}\text { Final density } \\
\text { of explosive, } \\
\mathrm{kg} / \mathrm{m}^{3}\end{array}$ & $\begin{array}{c}\text { Average } \\
\text { loading } \\
\text { density, } \\
\mathrm{kg} / \mathrm{m}\end{array}$ & $\begin{array}{c}\text { Temperature } \\
\text { of explosive, } \\
\mathrm{K}\end{array}$ & $\begin{array}{c}\text { Average } \\
\text { VOD, } \mathrm{m} / \mathrm{s}\end{array}$ \\
\hline $\begin{array}{l}\text { Complete } \\
\text { SME }\end{array}$ & - & 65 & 5.5 & 1140 & 11.81 & 335.15 & 4777.7 \\
\hline $\begin{array}{l}\text { Plastic tube } \\
\text { technique }\end{array}$ & 4 & 50 & 5.5 & 1100 & 9.09 & 335.75 & 4244.0 \\
\hline $\begin{array}{l}\text { Plastic bottles } \\
\text { technique }\end{array}$ & 15 & 60 & 6.5 & 1120 & 9.23 & 338.35 & 4206.9 \\
\hline DAG blasting & 400 & 55 & 6.0 & 1120 & 9.10 & 337.45 & 4641.6 \\
\hline
\end{tabular}

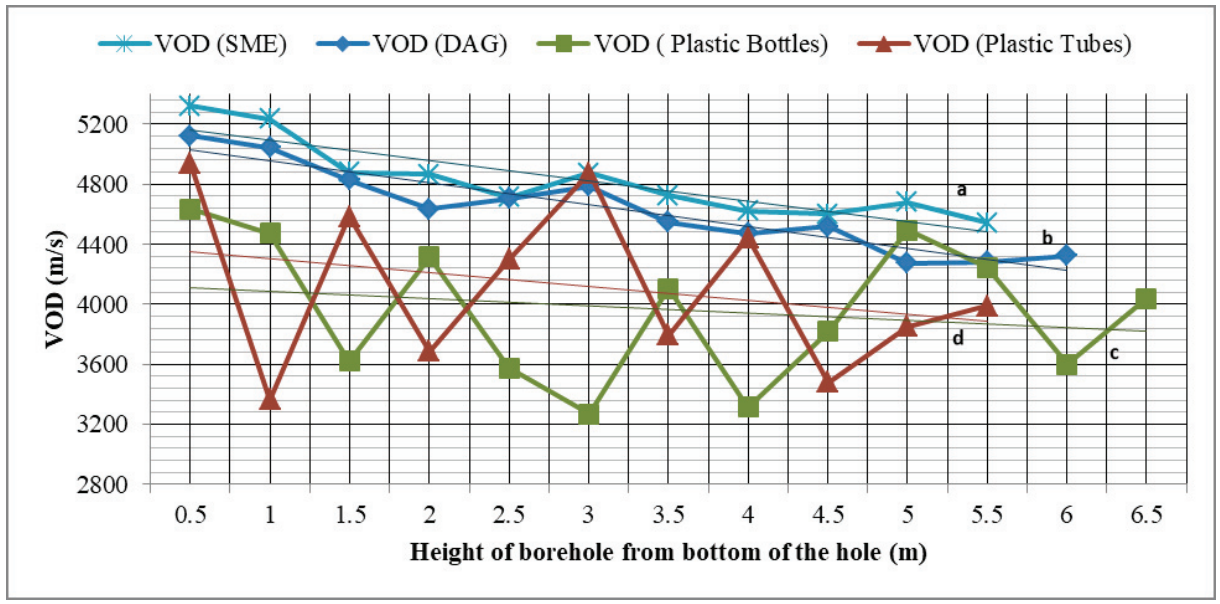

Fig. 10. VOD vs. height of explosive column for: a) SME, b) DAG, c) Plastic bottle, d) Plastic tubes 
The complete SME column attains a maximum VOD of $5321.6 \mathrm{~m} / \mathrm{s}$ which decreases to $4544.2 \mathrm{~m} / \mathrm{s}$ over the entire length of column (Curve a). Whereas, in case of DAG column, the VOD attains a maximum value of $5123.4 \mathrm{~m} / \mathrm{s}$ which decreases to $4274.2 \mathrm{~m} / \mathrm{s}$ over the entire length of column (Curve b). It must be noted that in the process of detonation, a shock wave generated is supported by the chemical reaction of explosive present in the reaction zone. When this shock wave travels through a medium, there is a sudden change in pressure, particle velocity, density and internal energy. Its velocity is the sum of the bulk sound speed and the particle velocity.

Though there is a minor fall in VOD values of DAG column, the detonation in DAG column is akin to the detonation in SME column (Curves a and b). A stable detonation is achieved with DAG column because the air gaps are very small in size and well distributed throughout the SME column. This also causes less attenuation of shock wave than those with plastic tubes and plastic bottles. Less attenuation can be attributed to the fact that relatively more amount of explosive is available in the vicinity of air gap so a larger primary reaction zone at high pressure and temperature is readily available for supporting the shock front. This insignificant fall in VOD does not affect the efficiency of detonation adversely.

The VOD in the SME columns with air gaps induced using plastic bottles and tubes are in general less than the VOD obtained with DAG column. Fig. 10 also indicates that a stable detonation is not achieved in these cases as the air gaps are not well distributed and are large in size. However, the detonation is found to be sustaining throughout the column. In case of SME column with air gaps induced using plastic bottles; the VOD attains a maximum value of $4636.3 \mathrm{~m} / \mathrm{s}$ which decreases to a minimum value of $3268.4 \mathrm{~m} / \mathrm{s}$. In case of SME column with air gaps induced using plastic tubes; the VOD attains a maximum value of $4935.9 \mathrm{~m} / \mathrm{s}$ which decreases to a minimum value of $3362.8 \mathrm{~m} / \mathrm{s}$.

The SME columns with air gaps generated using plastic bottles and plastic tubes are also resulting in sharp fall and rise of VOD (Curves c and d). This capricious behaviour is repeated over the entire length of the explosive column denoting attenuation of detonation waves in those specific regions. When the shock front approaches the air gap, the air gaps provide a compressible medium. In this region the velocity of the rear increases at a faster rate than the shock front as it is approaching a medium of higher density and pressure through which the shock front has already passed. The rear therefore eventually starts catching up the shock front, which results in attenuating the shock front. As the shock front keeps on travelling through the air gap, its velocity goes on reducing until an explosive zone is encountered which will support the detonation to proceed. Once the explosive zone is encountered the velocity of shock front starts increasing as the explosive is supporting the shock front by providing necessary energy to overcome the attenuation. Though in all cases where air gaps were used in, the net energy available for the detonation is enough to pass through the air gap. 
The blasts carried out using plastic bottles and plastic tubes techniques have large air gaps spread all along the length of explosive matrix. The detonation wave which comes across such large air gaps will get more attenuated since relative less amount of explosive is available unlike the DAG column. This causes reduction in the maximum value of VOD. Further, a fall of almost $1300 \mathrm{~m} / \mathrm{s}$ is noticed when the detonation wave encounters these air gaps (Curve $\mathrm{c}$ and $\mathrm{d}$ ). Such a large fall does not allow the detonation wave to regain its preferred VOD when the wave crosses the air gap. This results into a reduced detonation efficiency which may result in less percentage of energy doing the useful work.

\section{CONCLUSION}

This paper examines the detonation behaviour of the explosive column due to induction of air gaps. The VOD of complete SME column, DAG column and SME columns induced with plastic bottles or plastic tubes are measured. The VOD curves revealed that the detonation is propagating through the non-explosive zone in the column as no interruption in detonation at any place in the explosive column is discerned. The continuous VOD curves are further probed and a comparative investigation for variation in VOD for every $0.5 \mathrm{~m}$ of the explosive column is presented.

The investigation of conventional SME column indicates a stable detonation throughout the column with maximum VOD declining by about $14 \%$ at the topmost of the SME column. While using plastic bottles and plastic tubes as air gaps, the VOD is fluctuating in both the columns revealing unstable detonation. In these cases, there is a dip of about $30 \%$ between the highest and lowest values of VOD with many other abrupt falls detected in the entire columns. The reason for these sharp falls is attributed to the fact that in a non-explosive region the rear of the shock wave is catching up the shock front and attenuating the shock wave. The detonation progresses as usual once it reaches the explosive zone. These sharp fluctuations in VOD values can affect the explosive performance which results in a reduced detonation efficiency and less percentage of energy doing the useful work.

The investigation of DAG column indicates a stable detonation throughout the column with maximum VOD declining by about $16 \%$ at the top portion of the SME column. Among the explosive consumption reduction techniques, the detonation behaviour of DAG column is most similar to the conventional SME column. The VOD values obtained in DAG column are in general more than the cases where air gaps induced using plastic bottles and plastic tubes. These results reveal that though about $20 \%$ explosive is replaced with plastic balls, the explosive performance is not compromised. The effect on detonation pressure and blast performance due to induction of these air gaps can be further investigated. 


\section{ACKNOWLEDGEMENTS}

The authors want to acknowledge the managements of M/S Century Cement Limestone mines, Baikunth, Chhattisgarh, India and M/S Special Blasts Limited, Raipur, India, for providing necessary facilities for conducting the experiments. The authors also want to acknowledge Director, NIT Raipur, India for providing necessary funds for carrying out laboratory experiments and field trials.

\section{REFERENCES}

BERTA G., 1990, Explosives: An Engineering Tool, Italesplosivi-Milano.

BHANDARI S., 1997, Engineering Rock Blasting Operations. A.A. Balkema, Rotterdam, Brookfield.

CHIAPPETTA R.F., 1988, Blast monitoring instruments and analysis techniques with an emphasis on field application, Fragblast- International Journal of Blasting and Fragmentation, 1, 79-101.

CLARK G.B., 1971, Principles of Rock Fragmentation, John Wiley \& Sons.

COOPER P.W., 1996, Explosives engineering, John Wiley \& Sons.

CUDZILO S., KOHLICEK P., TRZEINSKI V.A., ZEMAN S., 2002, Performance of emulsion explosives, Combustion, Explosion and Shock Wave, 38(4), 463-469.

CUNNINGHAM C., 2006, Concepts of blast hole pressure applied to blast design, Fragblast, 10, 1-2, 33-45, DOI: 10.1080/13855140600852977.

GILTNER S.G., 2003, Relationship of booster size and Velocity of Detonation in production holes. Proc. 2nd World Conference on Explosives and Blasting Techniques, Prague, 363-368.

GONG Y., YAN S., WANG X., HE J., CHENG Y., 2017, Influence of glass microspheres content on underwater explosion energy of emulsion explosives, Journal of University of Science and Technology of China, 47(5), 443-447.

HATTORI K., FUKATSU Y., SAKAI H., 1982, Effect of the size of glass micro-balloons on the detonation velocity of emulsion explosive, Journal of Industrial Explosives Society, Japan, 43(5), 295-301.

KABWE E., CHANDA E.K., 2018, Velocity of detonation and fragmentation analysis to evaluate blasting efficacy, Journal of Rock Mechanics and Geotechnical Engineering, DOI: 10.1016/j.jrmge.2017.12.003.

KIM S.W., LEE S., KANG D.W., 2005, Method of blasting using air tubes charged in a blast hole. Proc. 3rd annual conference on explosives and blasting technique, ISEE, Orlando, Florida, 1, 59-72.

KONYA C.J., WALTER E.J., 1990, Surface Blast Design, Prenitice Hall, Englewood Cliffs.

LEE J., SANDSTOM F.W., CRAIG B.G., PERSSON P.A., 1989, Detonation and shock initiation properties of emulsion explosives. Proc. 9th Symposium on Detonation, Portland, Oregon, 573-582.

MARCHENKO L.N., 1982, Raising the Efficiency of a Blast in Rock Crushing, Soviet Mining Science, 18(5), 395-399.

MEL'NIKOV N.V., MARCHENKO L.N., 1971, Effective Methods of Application of Explosion Energy in Mining and Construction. 12th U.S. Symposium Dynamic Rock Mechanics, AIME, New York, Chap. 18, 350-378.

MEL'NIKOV N.V., MARCHENKO L.N., ZHARIKOV I.F., 1976, The Effect of An Air Cavity on The Motion During Ejection Blasting, Soviet Mining Science, 1(5), 501-507.

MEL'NIKOV N.V., MARCHENKO L.N., ZHARIKOV I.F., SEINOV N.P., 1979, Method of Enhanced Rock Breakage by Blasting, Soviet Mining Science, 15(6), 565-572.

MERTUSZKA P., KRAMARCZYK B., 2018, The Impact of Time on the Detonation Capacity of Bulk Emulsion Explosives based on Emulinit 8L, Propellants, Explosives, Pyrotechnics, 43(8), 799-804.

MESEC J., ŽGANEC S., KOVAČ I., 2015, In-hole velocity of detonation (VOD) measurements as a framework for the selection type of explosive, International Journal of Mining Science and Technology, 25(4), 675-680. 
MISHRA A.K., ROUT M., SINGH D.R., JANA S.P., 2018, Influence of Gassing Agent and Density on Detonation Velocity of Bulk Emulsion Explosives, Geotechnical and Geological Engineering, 36(1), 89-94.

NABIULLAH, PINGUA B.M.P, JAGDISH, AHMAD Z., CHAUDHARY M.K., AKHTAR J., 2005a, Study of cost effective bulk emulsion and their performance in different geo-mining conditions. Proc. 3rd National Seminar on Rock Excavation Techniques, Nagpur, 101-107.

NABIULLAH, PINGUA B.M.P, JAGDISH, KHAN M., EMRANUZZAMAM, 2005b, Study on explosives and their quality performance, Indian Mining and Engineering Journal, 44(1), 21-30.

OLUWOYE I., DLUGOGORSKI B.Z., GORE J., OSKIERSKI H.C., ALTARAWNEH M., 2017, Atmospheric emission of $\mathrm{NO}_{x}$ from mining explosives: A critical review. Atmospheric Environment, 167, 81-96, Doi: 10.1016/j.atmosenv.2017.08.006.

OUCHTERLONY F., NYBERG U., DENG J., 1997, Monitoring of large open cut rounds by VOD, PPV and gas pressure measurements, Fragmblast-International Journal of Blasting and Fragmentation, 1, 3-25.

PRADHAN G.K., PRADHAN M., 2013, Explosive energy distribution in an explosive column through use of non-explosive material- case study, Blasting in Mines - New Trends - The 10th International Symposium on Rock Fragmentation by Blasting, New Delhi, Taylor \& Francis, 81-89.

PRADHAN M., BALAKRISHNAN V., PRADHAN G.K., 2015, Use of discarded water bottles in blasting: An Innovative Enviro-Friendly Technique, International Journal of Chemical, Environmental \& Biological Sciences, 3(1), 51-53.

PRADHAN, MANOJ, 2010, Sleep Time - its Consequences on the Performance of Bulk Emulsion Explosive, Journal of Scientific \& Industrial Research, 69, 125-128.

QIUJIE W., LIU T., SEN X., DABIN L., LI, M., 2017, Study on Thermal Decomposition Characteristics of Ammonium Nitrate Emulsion Explosive in Different Scales, Journal of Energetic Materials, DOI: 10.1080/07370652.2017.1343408.

RAY S., 1991, Indigenous development of Bulk Delivery system for Explosives, Indian Mining and Engineering Journal, January, 34-40.

SHULIN N., 1993, Dead pressing phenomenon in emulsion explosives. Proc. 19th Annual Conference on Explosive and Blasting Techniques, International Society of Explosive Engineers.

STRIZHAK P.A., PISKUNOV M.V., VOLKOV R.S., LEGROS J.C., 2017, Evaporation, boiling and explosive breakup of oil-water emulsion drops under intense radiant heating, Chemical Engineering Research and Design, 127, 72-80, Doi:10.1016/j.cherd.2017.09.008.

SUMIYA F., HIROSAKI Y., KATO Y., 2002, Detonation velocity of pre-compressed emulsion explosives. Proc. 28th Annual Conference on Explosive and Blasting Techniques, International Society of Explosive Engineers.

WANG Y., LIU J., 2018, Calculation Model and Decoupling Coefficient Sensitivity Study of Periphery Hole for Eccentric Decoupled Charge in Highway Tunnels, Shock and Vibration, 1-11, DOI: 10.1155/ 2018/9734529.

XU S., TAN L., LIU J., CHEN X., JIANG W., CHEN Y., LIU D., 2016, Cause analysis of spontaneous combustion in an ammonium nitrate emulsion explosive, Journal of Loss Prevention in the Process Industries, 43, 181-188, DOI: 10.1016/j.jlp.2016.05.010.

XUGUANG W., 1994, Emulsion Explosives, Metallurgical Industry Press, Beijing.

ZANG Z.X., 2016, Rock fracture and blasting, Elsevier Inc. (Online).

ZHU Y., LU Y., GAO B., WANG D., YANG G., GUO C., 2017, Ultrasonic-assisted emulsion synthesis of well-distributed spherical composite CL-20@PNA with enhanced high sensitivity, Materials Letters, 205, 94-97, DOI: 10.1016/j.matlet.2017.06.064. 